\title{
Uninterruptible Energy Production in Standalone Power Systems for Telecommunications
}

\author{
E. F. F. Ribeiro ${ }^{1}$, A. J. Marques Cardoso ${ }^{1}$ and C. Boccaletti ${ }^{2}$ \\ ${ }^{1}$ University of Coimbra, FCTUC/IT \\ Department of Electrical and Computer Engineering \\ Pólo II - Pinhal de Marrocos, P - 3030-290, Coimbra, Portugal \\ Phone/Fax number: +351 239796 232/247, e-mail: eribeiro@co.it.pt, ajmcardoso@ieee.org \\ ${ }^{2}$ Sapienza University of Rome \\ Department of Electrical Engineering \\ Via Eudossiana, 18, 00184 Rome, Italy \\ tel: (+39) -06-44585762, fax: (+39)-06-4883235, e-mail: chiara.boccaletti@ uniroma1.it
}

\begin{abstract}
A continuously energy production is the most difficult and important feature to be guaranteed when designing a standalone power system for telecommunications. This paper focuses on a standalone power system for telecommunications already proposed in the literature, combining the most mature generators and technologies related to renewable energies and environment friendliness. It is important to know the operational problems, the best way to solve them and how to apply efficient maintenance. Reliability studies based on existent applications of renewable generators (some of them used in standalone power systems) help to know what to expect from their operational behaviour and to reduce time and costs in maintenance tasks. Notwithstanding their undoubted importance, they are not much recognised in literature, yet. The paper presents a brief review based on the few reliability reports about wind and photovoltaic systems available in the literature. Contributions and important aspects are discussed having in mind all the obstacles to achieve an uninterruptible power supply.
\end{abstract}

\section{Key words}

Standalone power systems, renewable energies, reliability, telecommunications, uninterruptible energy.

\section{Introduction}

Telecommunication has always been important for society growth and development. It started with smoke signals, in ancient times, and nowadays sophisticated equipments are used thanks to the technological progress. The world would not be as it is without telecommunications contribution. It assumes a basic importance in everyday life, political issues, scientific progress, weather problems, geographic difficulties, and many other subjects. The impact of telecommunications equipment improvement is huge and evident in all society activities.

All the necessary conditions to make telecommunications equipment work properly are achieved, not only by doing efforts in this specific area, but also by conceiving a robust power supply unit in order to satisfy all its requirements. The basic prerequisites imposed to telecommunications power systems are related to their safety, long life and uninterruptible power [1, 2]. They all depend on a good power system design and predictive maintenance. Other requirements are associated to the electrical characteristics of the telecommunications equipment, such as nominal voltage and operational range, noise and acceptable ripple levels.

Telecommunications networks were centred at the Central Office in the past. At the present time, new trends are being imposed to these networks by the technological improvements. They are getting closer to users and, subsequently, they are becoming dispersed. This also means new challenges in telecommunications power supply.

Due to recent advances in renewable energies equipment, standalone power systems are getting more and more suitable for this kind of applications. Besides being generated from natural sources and, subsequently, pollution free and naturally replenished, renewable energies are intermittent and this represents an obstacle to a proper telecommunications power supply. To overcome renewable energies limitations, a standalone power system combining different energy sources and energy storage devices seems to be an attractive way to supply telecommunications remote equipment in an autonomous way. Political actions and economical 
incentives, taking environmental concerns into account, promote this application as the best one to meet the telecommunications needs worldwide. In [3], different architectures are analysed and compared from an economical point of view, in order to get a procedure to select the most suitable solution. It is concluded that a gridline connection is not always the most appropriate solution to supply remote units.

Throughout this paper, standalone power systems for telecommunications will be presented and their operational problems will be reviewed, based on available reliability reports. Since uninterruptible energy production from standalone power systems is crucial to consider them as a suitable and reliable solution for telecommunications powering, some solutions are proposed to achieve it. These matters should deserve more attention in a near future.

\section{Factors influencing standalone power systems}

Several renewable sources have been through a good development in the last decades. Therefore, their combination would apparently provide a good uninterruptible power system. Different renewable generators would complement each other and energy storage components (such as fuel cells or batteries) would balance their discontinuous energy production. However, a lot of requirements have to be considered first. It is important to understand all the factors that influence its behaviour, in order to get the best of it. The most important factors are location, time and user needs (power). Location associates information about climate, energy sources availability and environment conditions. This information is very important to decide what kind of renewable generators can be chosen. For example, it is important to determine the hours of available sunlight and average wind speed. Time is also an important factor and two different approaches can be adopted (long and small period). In a long period approach, climate changes can assume a cyclical behaviour (e.g. seasons). Also user needs might be seasonal, but this is not the case of telecommunication systems. Instead of following a full/empty hours scheme, they are needed all the year long, therefore the load is expected to be relatively constant. A detailed study of the above factors is the first step to choose the required standalone power system topology and to make the best use of the local potentialities to supply the telecommunication equipment.

\section{Sizing standalone power systems}

After an in-depth study and an adequate data collection relevant to different renewable sources available in the site, the "ideal" standalone power system topology can be chosen. Another important step is to size the system. A standalone power system sizing depends on the load and on the collected source data (potentialities of the location). Due to the renewable energies intermittent behaviour, this kind of systems has to be oversized. In order to avoid very high costs, an optimization method should be used and a really good one is described in [4] for a standalone power system that includes wind and photovoltaic generators and a fuel cell. It also calculates the system initial cost.

\section{Standalone power systems for telecommunications}

Renewable generators have been employed in various applications (such as grid connection) with successful results. The knowledge already achieved in this area can be applied to power telecommunications equipment with many available options to realize it [5]. Different topologies have been successfully simulated and tested [5-12].

A good example of a standalone power system for telecommunications is shown in Fig. 1. When sunlight and wind are available, photovoltaic and wind generators produce energy to feed the telecommunication equipment. When the generated power exceeds the telecommunications equipment needs, the excess power supplies the electrolyzer and produces hydrogen until its storage is full. While wind and photovoltaic power is not enough to supply telecommunications equipment needs, the fuel cell produces the required power using already stored hydrogen.

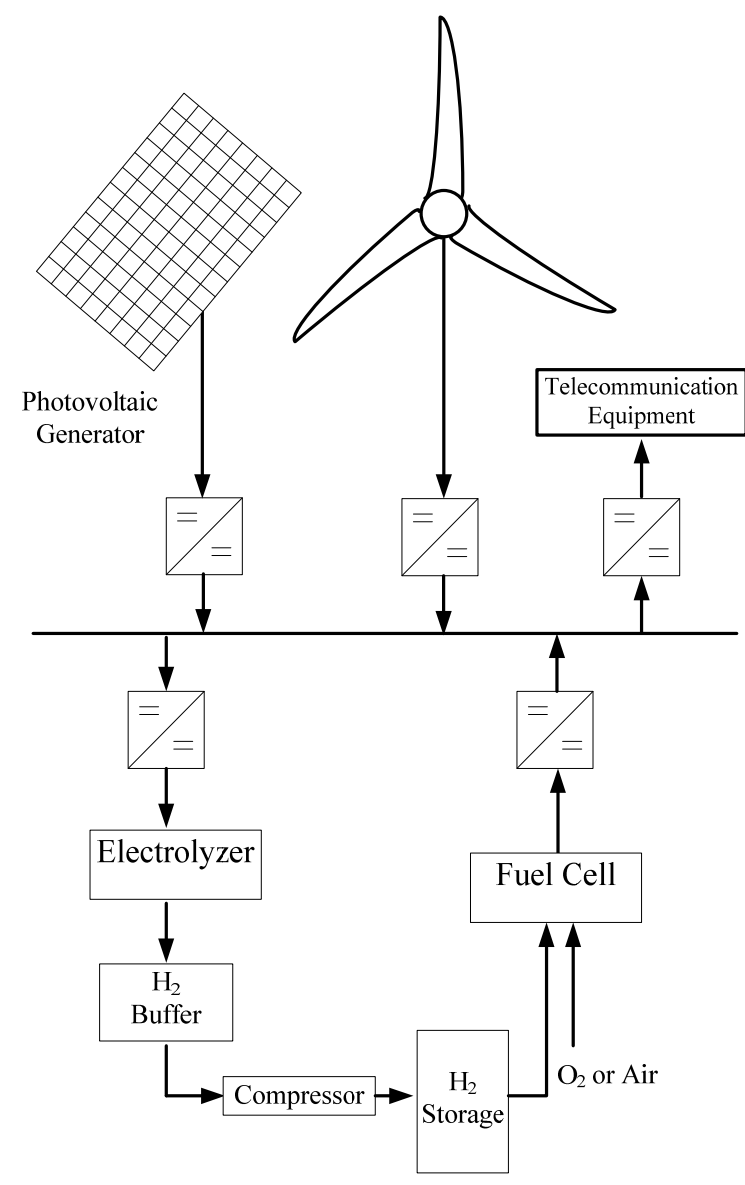

Fig. 1. Standalone Power System [13]. 


\section{Reliability problems during standalone power systems operation}

Although requiring lesser maintenance than other power systems (like the ones with a diesel generator, for example) and benefiting from a good reliability, standalone power systems are composed by fallible units. Maintenance experience and typical failures knowledge are critical to improve standalone power systems reliability. Two areas would mainly benefit from reliability studies: business and engineering. However, there are not so many studies on this subject available in the literature.

When planning a standalone power system, only initial cost is usually evaluated from a business point of view. This limited analysis is based on an optimistic performance which does not correspond to the actual one.

It is necessary to evaluate important factors influencing life-cycle costs, such as operation and maintenance costs. From an engineering point of view, a reliability study is essential to achieve a better performance of the standalone power system. It provides useful information to improve component selection and, subsequently, system design. Operation and maintenance strategies would also benefit from this study.

To perform a reliability study, it is necessary to analyze a few systems with similar components. This is the only way to achieve rigorous and useful statistical results. For each failure and maintenance event, performance data have to be collected, such as system identification, dates of failure and repair, type of event occurred and repair cost. There are different ways for monitoring standalone power systems, such as monthly readings or daily reports with sophisticated instruments. Of course, they are characterized by different accuracy and they can be more or less cost-effective depending on the application. Their importance is not limited to research purposes. In fact, predictive maintenance, which requires monitoring, is very important for telecommunications power supply systems, in order to achieve a continuously energy production.

Photovoltaic and wind generators are the most mature renewable generators to be included in a standalone power system. For this reason, a review of reliability problems on these two kinds of generator will be performed with reference to some studies available in the literature. Although these kinds of reports and studies have such a great importance, there are only a small number of reliability reports available for photovoltaic and wind generators.

\section{A. Photovoltaic Systems}

Photovoltaic systems are composed by two main parts: solar modules and power conversion unit. Solar modules are responsible for converting solar into electric energy. In order to get the bus voltage, a power conversion unit is necessary to be connected to them.

One of the advantages of photovoltaic generators, when compared with other generators, is their solid-state technology and, subsequently, easy maintenance. Moving parts such as tracking systems (whose function is to follow sun movement during the day with the aim of producing as much energy as possible) are not indispensable, however they help to get a better performance and to reduce energy cost [14].

Due to industry efforts in module manufacturing technology, in improving the performance and in reducing degradation, solar modules benefit from a high reliability [15] and their warranties last at least 20 years [16]. Unfortunately, power conversion units show a much lesser reliability [14-21]. Their warranty is between 3 and 5 years. There is really a huge discrepancy between reliability of both parts of a photovoltaic system, which means that during solar modules life, power conversion unit could be repaired and replaced many times [17]. Their reliability gets even worse if they are not designed and installed in a proper way or if the chosen technology is not adequately tested, which happens some times. According to [17], half of the studied systems did not have a good performance, long durability and a safety operation, due to an inappropriate installation, poor design and a choice of not certified technology.

If one component is not working in a totally healthy way, it will affect all photovoltaic system behaviour. If some of the solar modules fail, the whole system will continue to work, even though energy production will significantly reduce. Inverter failures can lead to a total system stoppage. The most common malfunctions are related to the fans breakdown (thermal management system), power semiconductor (transistors, diodes) and capacitor failures [16]. Indeed, capacitors are the most frequent component to fail and, subsequently, the quality of the DC bus capacitor seems to be the most critical issue. The capacitors used in these power systems are of the aluminium electrolytic type.

Other problems and failures related to photovoltaic systems include disconnecting switch problems (when fuses blown), source-circuit failures (fuse failures or blocking diode malfunction), module problems (damaged modules or ground problems), array wiring troubles and direct lightning strikes.

As mechanical moving supports, tracking systems could increase unreliability of photovoltaic systems. However, according to [14], a lot of improvements have been achieved and their maintenance does not seem critical.

\section{B. Wind Systems}

Wind turbine reliability is affected by the machine design and the manufacturing process. Wind turbines are conceived to last at least 20 years, but that is not usually 
achieved in practice, due to deficient design, unknown operating environment and manufacturing control issues [22].

Wind power systems require scheduled maintenance, such as periodic inspections, oil and filter changes, calibration and adjustment of sensors and actuators, blade cleaning and many other tasks specified in the manufacturer's manual. Although a careful planned maintenance allows component replacing and refurbishing, the need for unscheduled maintenance is never totally abolished. Its drawbacks are related to unpredictable costs and waiting time until the components are repaired during wind conditions good for energy production. They get even worse when they are related to a standalone power system, since they are located in remote sites and, subsequently, turbine accessibility is not easy. Time to repair damaged components is an important issue that affect system reliability when a failure occurs. The system will be stopped as long as the failure lasts and it depends on repair work, spare parts availability and human resources to handle with it. Different kinds of failures related to different wind turbine components will take different times to be fixed. Consistently, not only component failures rates, but also their downtime, are to be considered in reliability statistical studies.

Since wind turbines are composed by complex components, some of them are more easily prone to fail than others. The most frequent failures are related to gearbox and generator bearings, generator windings, gearbox torque arms, pitch drive electronics and power electronics converters [22]. Statistical studies confirm that the major number of failures is associated to the electrical system, followed by sensors and control systems [23, 24]. However, they are not responsible for the most part of the downtime of wind power systems. Other component failures are even more critical. For example, gearboxes are of main concern [23, 24]. Their longest downtime when they have to be repaired is related to their large size and hard replacement (requiring specific equipment to be moved, such as cranes) and the need to order spare parts to fix them [23]. It is complicated to avoid their breakdown, because it is mainly caused by inherent mechanical wear. According to [23], for a typical turbine gearbox failures account for $20 \%$ of wind power system downtime. The average repair time is about 256 hours.

The total number of failures in a wind power system and their evolution according to turbine age allows to estimate the lifetime expectancy. They allow to compare different systems as well, as, for example, systems with different levels of installed power. High-power systems (above $1000 \mathrm{~kW}$ ) have higher annual failure rates than wind systems with lower installed power [23]. If the evolution of failure rates is analysed, there are also differences between highand low-power systems. Annual failure rates in high- power systems seem to increase, while in low-power systems they decrease after the first years of operation until they reach their decaying time [23].

Improvements have been achieved in wind power systems and they have reached an availability of $98 \%$, taking good planned maintenance and efficient repairs into account. It seems to be a good result, however, uninterruptible energy production is imperative nowadays, in particular for telecommunication power systems. Therefore, a vast number of challenges need to be accomplished. For example, gearbox development has contributed to diminish their failure rates, but repair time seems to get longer [23].

\section{Recommendations to achieve an uninterruptible energy production in a standalone power system}

A few steps to achieve uninterruptible energy production have already been presented and emphasized. Starting from planning until operation problems, some recommendations can be summarized to meet telecommunications equipment energy needs, having in mind all the discussed reliability problems.

Uninterruptible energy production and good reliability in standalone power systems start with planning.

To build the standalone power system, reliable components must be used and standards already defined must be followed. A good infrastructure must be accurately planned with the aim of minimizing failures and to make as easy as possible all required maintenance and repairs. Necessary maintenance equipments should be also included. For example, lifting equipment should be mounted when the standalone power system includes wind turbines [25]. All equipment should be listed and quantified in an inventory.

Once the system is installed and started up, it is necessary to keep the standalone power system at its best performance level. The cited reliability studies play an important role. They allow to save time and money in tasks related to maintenance. Some components that require special attention can be identified, due to their expensive price, repair time or criticality for the process. Also a logistic plan including failure events and repair tasks can be developed based on reliability studies information.

Failure modes and their causes are also another important matter to study. Failure mode analyses help to prevent their evolution to a possible system shutdown or to a catastrophic level. Failure cause analyses help to learn from it. All failures and problems related to standalone power systems should be faced as opportunities for improvements.

Standalone power system maintenance should be based in remote monitoring data. This involves a comprehensive distribution of sensors in order to get as much useful information as possible of the entire 
system. Such information about performance and operational system behaviour must be communicated to maintenance personnel using phone lines, line-ofsight microwave communication or satellites [25]. Robust sensors must be chosen to avoid their malfunction. Their purpose is to spy system behaviour and to diagnose possible failures, preventing huge problems as soon as possible and keeping the whole system working in a healthy way.

Another important issue to be considered in standalone power system and responsible for many malfunctions is vandalism. According to [19], it is responsible for $60 \%$ of the maintenance costs of photovoltaic standalone power systems. Therefore, safety conditions should be guaranteed for the standalone power systems, such as isolating it with fences and barbed wire.

\section{Conclusions}

An uninterruptible energy production is the uppermost requirement of telecommunications power systems. It is indispensable to have a full understanding of how standalone power systems are influenced by external factors related to their remote locations, to size them properly and to keep their performance at the higher level with a suitable maintenance. Reliability reports help in what is concerned to maintenance and operational behaviour. Their importance is huge and their recognition is growing due to the standalone power system improvements and practical experience.

In the paper, the main reliability problems are described, according to a few number of available reliability reports. There is still not enough information on the subject, but it is a base to develop important contributions to achieve the best performance and operation of a standalone power system. Further work should be performed. Here only available results concerning photovoltaic and wind generators are presented. Similar results should be obtained for other important components, such as fuel cells. Indeed, a lot of challenges still need to be faced. Chemical troubles that affect fuel cells reliability are still unknown.

As soon as standalone power systems are used in remote sites to supply telecommunications equipment, reliability reports should be a priority to improve their operation, performance and design.

\section{References}

[1] Reeve, D., DC Power System Design for Telecommunications, John Wiley and Sons, USA (2007).

[2] Gumhalter, H., Power Supply in Telecommunications, Springer-Verlag, Berlin (1995).
[3] Vazquez, M.; Quiaones, C.; Rascon, M., "Procedure to select the optimised power architecture for a telecommunications network of remote units", 21st International Telecommunications Energy Conference, INTELEC 1999, June 1999.

[4] D. B. Nelson, M. H. Nehrir, and C. Wang, "Unit sizing of stand-alone hybrid wind/PV/fuel cell power generation systems", IEEE Power Engineering Society Meeting 2005, Vol. 3, pp 2116-2122, 12-16 June 2005.

[5] Boccaletti, C.; Fabbri, G.; Santini, E., "Innovative solutions for stand alone system powering", 29th International Telecommunications Energy Conference, INTELEC 2007, pp. 294-301, Sept. 30 2007-Oct. 4, 2007.

[6] Lehman, P. A.; Chamberlin, C. E.; Zoellick, J. I.; Engel, R. A., "A photovoltaic/fuel cell power system for a remote telecommunications station", Conference Record of the Twenty-Eighth IEEE Photovoltaic Specialists, pp.1552-1555, 2000.

[7] Tanezaki, S.; Matsushima, T.; Muroyama, S., "Stand-alone hybrid power supply system composed of wind turbines and photovoltaic modules for powering radio relay stations", 25th International Telecommunications Energy Conference, INTELEC 2003, 2003.

[8] Hashimoto, S.; Yachi, T.; Tani, T., "A new standalone hybrid power system with wind generator and photovoltaic modules for a radio base station", 26th Annual International Telecommunications Energy Conference, INTELEC 2004, pp. 254-259, 19-23 September 2004.

[9] Salas, V.; Olias, E.; Rascon, M.; Vazquez, M.; Quifiones, C., "Hybrid powering system for standalone remote telecom applications", 22nd International Telecommunications Energy Conference, INTELEC 2000, pp. 311-316, 2000.

[10] Bitterlin, I. F., "Modelling a reliable wind/PV/storage power system for remote radio base station sites without utility power”, Journal of Power Sources, Volume 1, 2005.

[11] Kato, N.; Kurozumi, K.; Susuld, N.; Muroyama, S., "Hybrid power-supply system composed of photovoltaic and fuel-cell systems", 23rd International Telecommunications Energy Conference, INTELEC 2001, pp. 631-635, 14-18 October 2001.

[12] Marquet, D.; Foucault, O.; Aubree, M., "SollanDimsol R\&D Project, Solar and Renewable Energy in France Telecom", 28th Annual International Telecommunications Energy Conference, INTELEC 2006, 1-8 September 2006.

[13] Ø. Ulleberg, "Stand-alone power systems for the future: optimal design, operation and control of solar-hydrogen energy systems”, PhD Thesis, Norwegian University of Science and Technology, Norway, 1998.

[14] Moore, L.; Post, H.; Hayden, H.; Canada, S.; Narang, D., "Power Plant Experience at Arizona Public Service: a 5-year assessment”, Progress in Photovoltaics: Research and Applications, Volume 13, number 4, pp. 353-363, 2005. 
[15] Dhere, N.G., "Reliability of PV modules and balance-of-system components," Conference Record of the Thirty-First IEEE Photovoltaic Specialists, pp. 1570-1576, 3-7 January 2005

[16] Ristow, A.; Begovic, M.; Pregelj, A.; Rohatgi, A., "Development of a methodology for improving photovoltaic inverter reliability", Transactions on IEEE Industrial Electronics, Volume 55, number 7, pp 2581-2592, July 2008.

[17] Wiles, J.C.; Brooks, B.; Schultze, B. O., "PV installations, a progress report", Conference Record of the Twenty-Ninth IEEE Photovoltaic Specialists Conference, pp. 1461-1464, 19-24 May 2002.

[18] Begovic, M.; Pregelj, A.; Rohatgj, A., "Fouryear performance assessment of the $342 \mathrm{~kW} \mathrm{PV}$ system at Georgia Tech", Conference Record of the Twenty-Eighth IEEE Photovoltaic Specialists, pp.1575-1578, 2000.

[19] Maish, A.B.; Atcitty, C.; Hester, S.; Greenberg, D.; Osborn, D.; Collier, D.; Brine, M., "Photovoltaic system reliability", Conference Record of the Twenty-Sixth IEEE Photovoltaic Specialists, pp.1049-1054, 29 Sep-3 Oct 1997.

[20] Canada, S.; Moore, L.; Post, H.; Strachan, J., "Operation and maintenance field experience for off-grid residential photovoltaic systems”, Progress in Photovoltaics: Research and Applications, Volume 13, number 1, pp. 67-74, 2005.

[21] Pregelj, A.; Begovic, M.; Rohatgi, A., "Impact of inverter configuration on PV system reliability and energy production", Conference Record of the Twenty-Ninth IEEE Photovoltaic Specialists, pp. 1388-1391, 19-24 May 2002.

[22] Walford, C. A., "Wind Turbine Reliability: Understanding and minimizing wind turbine operation and maintenance costs”, Sandia Report, USA (2006).

[23] Ribrant, J.; Bertling, L. M., "Survey of Failures in Wind Power Systems With Focus on Swedish Wind Power Plants During 1997-2005", IEEE Transaction on Energy Conversion, Volume 22, number 1, pp.167-173, March 2007.

[24] Peinke, J.; Schaumann, P.; Barth, S, "Wind Power”, Springer Berlin Heidelberg, 2007.

[25] Rogers, A. L.; Manwell, J. F.; McGowan, J. G., Ellis, A. F.; "Design requirements for mediumsized wind turbines for remote and hybrid power systems”, Renewable Energy, Volume 26, number 2, pp. 157-168, 2002. 